\title{
ANALISIS SEMIOTIK PADA IKLAN-IKLAN AQUA DI MEDIA TELEVISI
}

\author{
Bunga Diantirta Yapati Puteri \\ Universitas Negeri Surabaya, diantirtayp@gmail.com
}

\begin{abstract}
The analysis of this paper is related to the myth analysis of the adevertisements of Aqua water drink that are advertised in the television. Relating to this, these myth of Aqua has sent the messages to the readers' mind. These myth can the readers' mind to choose something and make a decision. In those advertisements of Aqua, the myth are sent by considering the location of video advertisement, colors choosing, ornamemts adding, time settings, choosing of musics, the characters of actors or actress, the compny image, and choosing of sentences that can persuade the readers to buy the Aqua product and specfifically make this myth becomes one of factors of influencein buying something. This analysis uses the library study to know and to observe the phenomena or conditions in producing the video advertisement of the water drink product. For this, the qualitative data are used to know the description of the myth of the product advertised and its supporting factors. The descriptive qualitative analysis is applied to analyse these data. The result of research proves that the majority of myth that involved in the advertisement can mention Aqua is the best hygiene water drink the people consume. These advertisements of Aqua can make the audiences or people believe that Aqua is the right water drink for the body health, especially in reducing dehydration and increasing the concentration of the person that consumes it.
\end{abstract}

Keywords: semiotics, myth, the advertisemnt

\section{PENDAHULUAN}

Membahas dan membicarakan tentang iklan baik itu iklan di televisi, koran, majalah, maupun iklan yang bertebaran di sepanjang jalan atau trotoar merupakan topik atau hal yang hangat dan sering diperbicangkan. Menyangkut hal tersebut, iklan yang ditayangkan di media visual maupun cetak itu amatlah beraneka ragam; mulai dari iklan produk barang kebutuhan pokok hingga produk barang bermerk dari perusahaan yang ternama. 
Berkorelasi dengan hal di atas, iklan adalah alat atau media komunikasi yang digunakan sebagai sebuah bagian atau elemen dari pemasaran dan promosi suatu produk tertentu.

Karena iklan bertujuan atau berfungsi untuk mempromosikan suatu produk tertentu, pastinya iklan menggunakan kalimat, frase, atau jargon yang persuasif atau dengan kata lain, berupaya merayu para khalayak umum agar membeli, mengkonsumsi, atau mempergunakan produk yang diiklankan tersebut. Nah, kalimat, frase, atau jargon yang dipergunakan di dalam iklan itu pastilah yang menarik, mudah diingat, dan mudah dipahami oleh semua kalangan; baik dari kalangan yang berpendidikan rendah sampai kaum intelektual atau cendekiawan.

Menyangkut hal tersebut di atas, isi atau kandungan iklan yang ditayangkan tersebut baik melalui media visual atau cetak itu pastilah mengandung pesan-pesan tertentu kepada para khalayak umum. Nah, pesanpesan tersebut akan tertanam sebagai sebuah "mitos" bagi para konsumen dan pada akhirnya produk yang dipromosikan tersebut akan membuat "image" tersendiri di benak para konsumen.

Dalam hal ini, iklan yang akan dijadikan objek kajian dan yang akan dianalisis di dalam pembahasan ini adalah iklan tentang produk salah satu air mineral yang sudah terkenal sejak lama, yaitu Aqua yang diproduksi oleh PT. Tirta Investama, Klaten. Alasan mengapa penyusun makalah ini memilih Aqua karena Aqua adalah produk yang sudah lama ada di pasaran dan menjadi pilihan para konsumen, khususnya di Indonesia. Selain itu, alasan lain yang dikemukakan oleh penyusun makalah ini mengapa memilih Aqua karena Aqua telah menjadi "mitos" atau memiliki "image" tersendiri di kalangan konsumen produk air mineral, sebagaimana misal jika seorang konsumen produk air mineral akan membeli air mineral di sebuah toko atau distributor itu pastilah yang pertama kali disebutkan atau ditanyakan adalah Aqua dan bukanlah merk atau nama produk air mineral lainnya. 
Menyangkut hal tersebut di atas, di dalam iklan Aqua, terutama yang ditayangkan di televisi, banyak pesan yang di dalamnya mengandung "mitos" bahwasanya dengan mengkonsumsi Aqua kita dapat lebih fokus, terutama dalam menjalankan aktifitas. Berkaitan dengan hal ini, menarik untuk dianalisis mengenai pesan atau "mitos" yang terkandung secara implicit di dalam iklan air minum AQUA. Adapun rumusan masalah di makalah ini adalah: pesan apa atau mitos (myth) apa yang secara implisit terkandung atau ingin disampaikan di dalam iklan AQUA tersebut?

Dikorelasikan dengan hal di atas, penelitian yang terkait dalam makalah ini atau penelitian yang temanya hamper sama dengan penelitian ini adalah penelitian berjudul "A Semiotic Analysis of Housing Advertisements in SURYA Daily Newspaper" yang disusun atau ditulis oleh Bunga D. Y. Puteri dari Universitas Negeri Jember. Meskipun begitu, makalah ini amatlah berbeda bila dikomparasikan dengan penelitian tersebut di atas, karena objek atau hal yang dijadikan penelitian amatlah berbeda. Jika di dalam penelitian yang penelitian berjudul "A Semiotic Analysis of Housing Advertisements in SURYA Daily Newspaper" yang disusun atau ditulis oleh Bunga D. Y. Puteri dari Universitas Negeri Jember (UNEJ) tersebut sebelumnya menggunakan objek perihal iklan rumah atau segala sesuatu tentang perumahan yang ada di iklan surat kabar atau Koran SURYA, sedangkan makalah yang ditulis ini menggunakan objek kajian berupa 3 buah iklan produk air minum AQUA yang berformat audio-visual yang ditayangkan beberapa bulan belakangan ini di beberapa stasiun televisi di Indonesia.

Tujuan utama makalah ini adalah untuk mengetahui dan menguraikan pesan(message) apa atau mitos (myth) apa yang secara implisit terkandung atau ingin disampaikan di dalam iklan AQUA tersebut. Secara keseluruhan, makalah ini akan membahas pesan (message) atau mitos (myth) apa yang terkandung secara implisit atau ingin disampaikan di dalam iklan air minum mineral AQUA. 
Di dalam makalah yang berjudul Analisis Semiotik pada Iklan-iklan Aqua di Media Televisi ini, teori yang digunakan adalah teori semiotik terutama teori mitos (myth) yang dicetuskan oleh Roland Barthes, filosof Prancis yang meneruskan teori semiotik dari Saussure.

\section{PEMBAHASAN}

Di dalam makalah ini, penyusun berusaha menjelaskan atau menguraikan pesan (message) atau mitos (myth) apa yang terdapat secara implisit atau yang coba disampaikan di dalam iklan air minum mineral Aqua. Adapun teori yang dipakai adalah teori mitos (myth) yang dikembangkan oleh Roland Barthes. Teori mitos (myth) ini sendiri merupakan bagian dari teori semiotik yang dirintis oleh Saussure. Teori ini menjelaskan bahwa "mitos" itu merupakan salah satu jenis ujaran atau ungkapan pembicaraan. Hal ini berdasar kutipan yang berbunyi: "myth is, in its most basic form, a special type of speech. What Roland Barthes meant was that a myth isn't just a genre of story, it was a way of saying something." Berkaitan dengan hal ini, dapat diketahui bahwa "mitos" yang dimaksud oleh Roland Barthes itu bukanlah sebuah tipe atau jenis cerita, melainkan sebuah tipe ujaran atau ungkapan pembicaraan yang spesifik. Menyangkut hal ini, Roland Barthes menambahkan bahwa "mitos" itu merupakan bagian dari sebuah sistem komunikasi yang di dalamnya memiliki atau menimbulkan arti atau makna tertentu. Hal ini diperkuat oleh kutipan dari Culturalstudiesnow (2012) yang berbunyi sebagai berikut:

"Barthes defines myth a speech. Myth is speech in that is part of a system of communication in which it bears meaning. By this definition Barthes expands on Levi-Strauss' perception of myth to include every symbol which conveys meaning (be it a spoken or written text, and image, a design etc. and even human actions such as sunbathing)." 
Dari kutipan di atas, dapat diketahui bahwa "mitos" itu tidak bisa dipisahkan dari sistem komunikasi. Di kutipan ini pula, dapat diketahui bahwa Barthes menambahkan atau lebih menguraikan lagi teori dari Levi Strauss yang berkaitan dengan "mitos" yang di dalamnya mencakup simbol-simbol tertentu yang memiliki atau menimbulkan makna atau arti.

Menyangkut hal di atas, "mitos" itu sendiri bisa terdapat atau ada di dalam komunikasi yang berupa tulisan (written modes/ written form) hingga media komunikasi yang berbentuk visual maupun audio visual seperti iklan televisi, media massa, foto, laporan, dan media publikasi lainnya. Hal ini diperkuat oleh statemen dari Roland Barthes (1972: 110) yang menyatakan bahwa: "Myth is not defined by the object, the message, but the way in which utters the message. Everything can be a myth if it is said, speech and a type of social usage." Berdasar kutipan di atas itu, dapat disimpulkan bahwa segala sesuatu itu bisa dikategorikan mitos terutama jika berupa sesuatu yang bisa dikomunikasikan khususnya secara lisan atau ujaran dan yang dihubungkan dengan kegunaan social. Hal ini didukung oleh kutipan dari Culturalstudiesnow (2012) yang berbunyi sebagai berikut: "For Barthes, every cultural product had meaning, and this meaning is conditioned by ideology, i.e. myth, and therefore any cultural product can be the subject of mythological analysis and review." Dari pernyataan ini, dapat diketahui bahwa "mitos" itu bisa dideskripsikan sebagai produk atau hasil kultur atau budaya yang menyampaikan makna atau pesan atau ideologi tertentu di dalamnya.

Dikorelasikan dengan "mitos" pada statemen di atas, Roland Barthes (1972: 115) menggambarkan atau mendeskripsikan struktur "mitos" tersebut ke dalam sebuah bagan atau figure diagram seperti di bawah ini: 


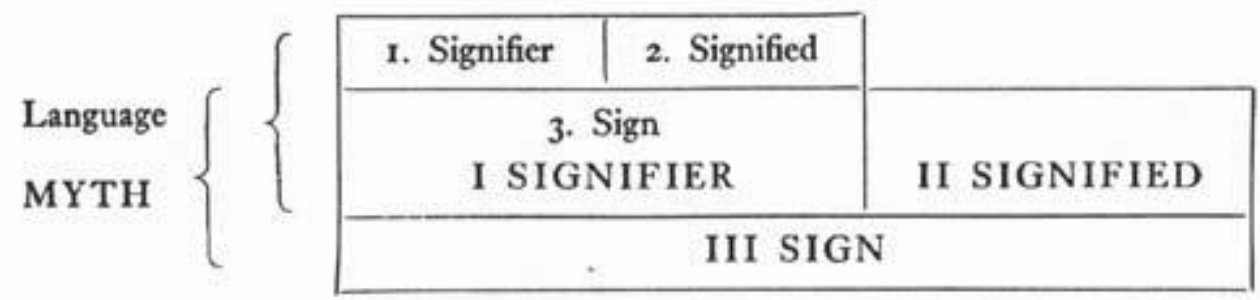

Dari bagan atau figure diagram di atas, dapat diketahui bahwa sebenarnya "mitos" itu dihubungkan dengan system tanda, penanda, dan pertanda (sign, signified, dan signifier). Untuk hal ini, Roland Barthes kemudian membagi atau mengklasifikasikan hal tersebut menjadi denotation, connotation, dan myth seperti yang tampak pada kutipan berikut, terutama yang dikutip dari Ceasefire magazine (2016):

"The first (denotative) order (or level) of signification is seen as primarily representational and relatively self-contained. The second (connotative) order of signification reflects 'expressive' values which are attached to a sign. In the third (mythological) order of signification the sign reflects major culturally-variable concepts underpinning a particular worldview - such as masculinity, femininity, freedom, individualism, objectivism, Englishness and so on."

Dari kutipan di atas, dapat diketahui bahwa di dalam ilmu semiotic itu selain terdapat Mitos, juga terdapat denotation (ungkapan denotasi) dan connotation (ungkapan konotasi) yang kesemuanya itu bisa saja terkandung di dalam iklan, media massa, ataupun bentuk audio-visual lainnya. Namun, di dalam makalah ini, penulis atau penyusun makalah ini hanya menjelaskan atau menguraikan "mitos" yang terkandung secara implicit atau yang ingin disampaikan di dalam iklan air mineral AQUA.

Adapun “mitos" yang dikembangkan oleh Roland Barthes itu menurut situs ilmiah Ceasefiremagazine (2016)itu merupakan sesuatu yang bersifat natural dan mengandung kesan, tujuan, dan makna tertentu seperti yang tampak dalam pernyataan berikut: 
"Myths are not read as statements of particular actors, but asoutgrowths of nature.They are read as 'innocent' speech from which ideology and signification are absent. To consume a myth is not to consume signs, but images, goals and meanings."

Dari kutipan di atas, dapat diketahui bahwa "mitos" itu terkandung tidak hanya statemen atau pernyataan kosong belaka, tetapi mengandung pesan (message), kesan (image), tujuan (goal), dan makna (meaning) tertentu. Menyangkut hal ini juga diperkuat atau didukung oleh kutipan yang dikutip dari Culturalstudiesnow (2012) yang berbunyi: "Barthes expands on the perception of myth to include every symbol which conveys meaning. "Menurut kutipan di atas, khalayak dapat mengetahui bahwasanya Roland Barthes memperluas pandangan tentang "mitos" yang mana di dalamnya sudah mencakup setiap simbol yang mengandung pesan (message) atau makna secara implicit.

Mengenai hal di atas, "mitos" itu sendiri diperlakukan seperti atau layaknya metafora yang membantu orang-orang dalam mempersepsikan pengalaman yang berkaitan dengan budaya. Hal ini didukung statemen "Myths can be seen as extended metaphors. Myths help us to make sense of experiences within a culture. They express and serve to organize ways of conceptualizing things within culture."(Culturalstudiesnow, 2012)

Juga, berkaitan dengan "mitos", Roland Barthes di dalam karyanya Mythologies (1972) mengungkapkan atau menyatakan:

"For Barthes, myths serve the ideological function of naturalization. Their function is to naturalize the cultural - in other words, to make dominant cultural and historical values, attitudes and beliefs seem entirely 'natural', 'normal', self-evident, timeless, obvious 'common-sense' - and thus objective and 'true' reflections of 'the way things are'."

Nah, dari kutipan pernyataan Barthes di atas tersebut, dapat diketahui bahwasanya "mitos" itu memberikan fungsi ideologis terutama yang berhubungan dengan 
pembudayaan atau naturalisasi. Menyangkut hal di atas, sebuah kutipan dari Lakoff dan Johnson yang berasal dari Culturalstudiesnow (2012) menyatakan:

"A myth which allies itself with scientific truth, rationality, accuracy, fairness and impartiality and which is reflected in the discourse of science, law, government, journalism, morality, business, economics and scholarship. Myths can function to hide the ideological function of signs and codes. The power of such myths is that they 'go without saying'."

Berdasarkan kutipan tersebut di atas, dapat diketahui bahwa "mitos" itu dapat tercermin atau terefleksikan di dalam wacana-wacana atau diskursus-diskursus ilmu pengetahuan, hukum, pemerintahan, jurnalistik, moralitas, bisnis, ekonomi, dan pendanaan atau beasiswa. Mitos ini memiliki daya atau kekuatan untuk menyampaikan pesan (message) secara implicit (go without saying).

Dikorelasikan dengan hal sebelumnya di atas, "mitos" juga bisa merefleksikan konsep-konsep yang utamanya berkaitan dengan budaya, seperti hal-hal maskulinitas, feminisme, kebebasan atau kemerdekaan, obyektivitas, kebahasa Inggris-an, dan hal-hal lainnya seperti yang tampak dari Culturalstudiesnow (2012)berikut ini:

"Inthe third order of signification, the myth reflects major culturally-variable concepts underpinning a particular worldview - such as masculinity, femininity, freedom, individualism, objectivism, Englishness and so on."

Dari kutipan di atas, dapat diketahui bahwasanya "mitos" itu merefleksikan konsep-konsep budaya yang mencakup maskulinitas, feminism, kebebasan atau kemerdekaan, dan hal-hal lain. Dari uraian atau penjelasan teori Roland Barthes tentang "mitos" (myth) tersebut, selanjutnya akan diberikan contoh pengimplementasian dari teori "mitos" tersebut. Adapun contoh pengimplementasian teori "mitos" dari Roland Barthes itu dapat kita lihat dari 
kutipan Culturalstudiesnow (2012) yang memuat foto tentang artis Marilyn Monroe berikut.

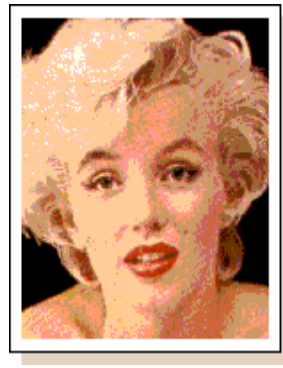

"At the denotative level, this is a photograph of the movie star Marilyn Monroe. At a connotative level, we associate this photograph with Marilyn Monroe's star qualities of glamour, sexuality, beauty - if this is an early photograph but also with her depression, drug-taking and untimely death if it is one of her last photographs. At a mythic level, we understand this sign as activating the myth of Hollywood: the dream factory that produces glamour in the form of the stars it constructs, but also the dream machine that can crush them - all with a view to profit and expediency"

Menurut kutipan di atas, foto Marilyn Monroe di atas itu secara semiotik bisa dijelaskan melalui 3 (tiga) ranah atau level. Pertama, secara denotatif, foto tersebut di atas adalah betul tentang Marilyn Monroe, seorang bintang film atau artis film. Kemudian, foto di atas tersebut bisa memberikan kesan (image) secara konotatif (connotative level) pada khalayak bahwa foto tesebut di atas bisa diasosiasikan dengan keglamoran, sensualitas, kecantikan, dan kehedonisan hidup Marilyn Monroe, yang akhirnya berujung pada kematian akibat penggunaan narkoba, jika saja foto tersebut dikaitkan dengan foto Marilyn Monroe terakhir menjelang detik-detik akhir hidupnya. Lalu, yang terakhir dapat dikaji dari foto di atas adalah melalui segi "mitos" (myth). Menyangkut hal ini, pesan (message) yang secara implicit tampak atau yang ingin disampaikan adalah bahwasanya Marilyn Monroe itu merupakan simbol atau manifestasidari mitos perfilman Hollywood Amerika Serikat yang memunculkan kehidupan glamor artis-artis, yang kelak di kemudian hari bisa menghancurkan reputasi dan karir artis-artis itu sendiri.

Berdasarkan uraian dan contoh pengimplementasian dari teori "mitos" di atas, di dalam makalah ini, penulis akan mengkaji atau ingin mengetahui pesan (message) yang secara implicit terdapat di dalam iklan AQUA atau pesan 
Bunga Diantirta, Analisis Semiotik pada...(hlm. 160 - 176)

(message) yang ingin disampaikan di dalam iklan AQUA. Menyangkut hal ini, penulis mengkaji empat objek iklan AQUA di beberapa bulan terakhir yang muncul di media massa, terutama di siaran televisi dan iklan visual.

Yang pertama dikaji adalah iklan air minum mineral AQUA yang dibintangi oleh artis Dian Satrowardoyo. Iklan yang dibintangi oleh Dian Sastroini memunculkan salah satu adegan yang dikaitkan dengan film Ada Apa Dengan Cinta 2 (AADC2) seperti potongan adegan berikut:

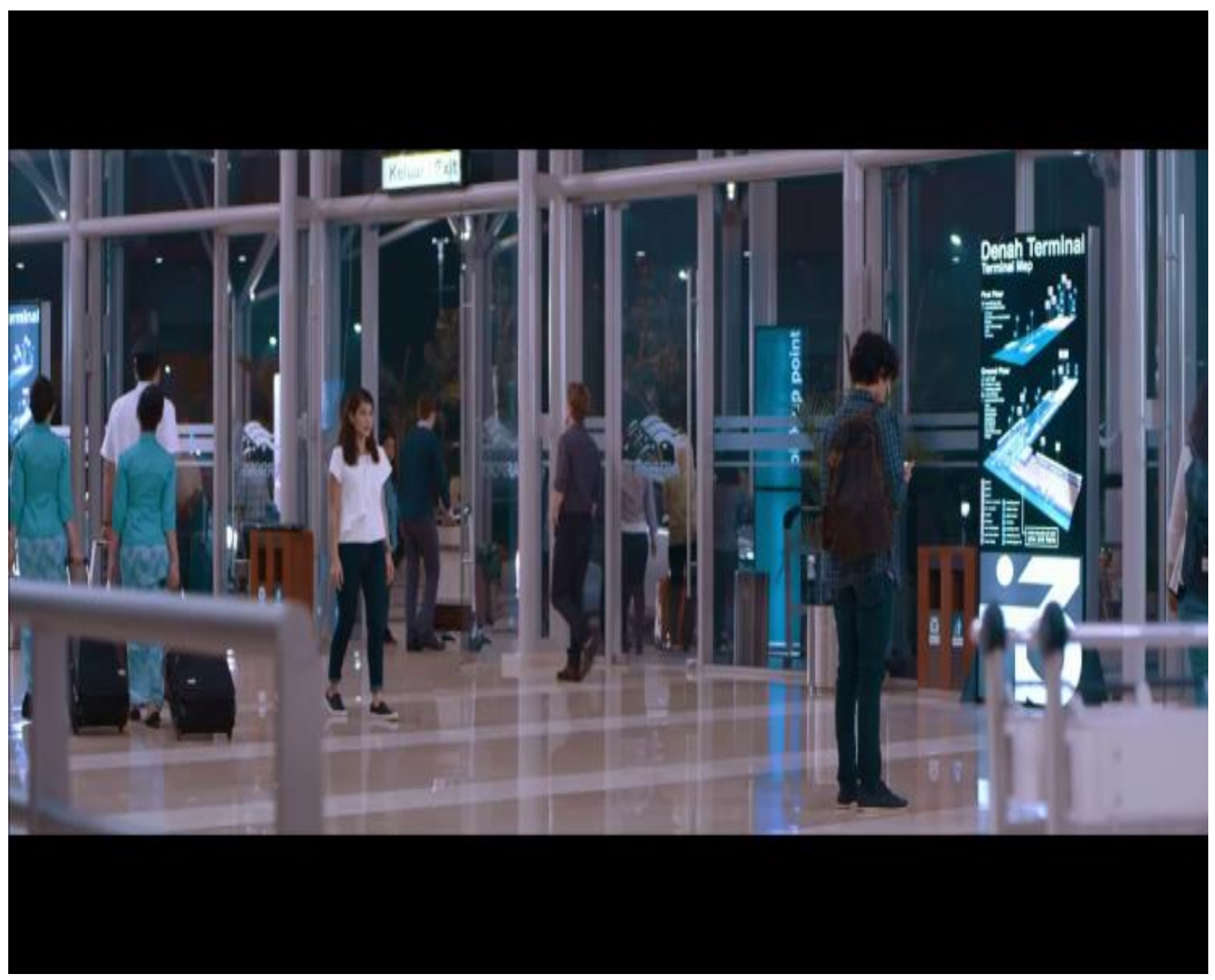




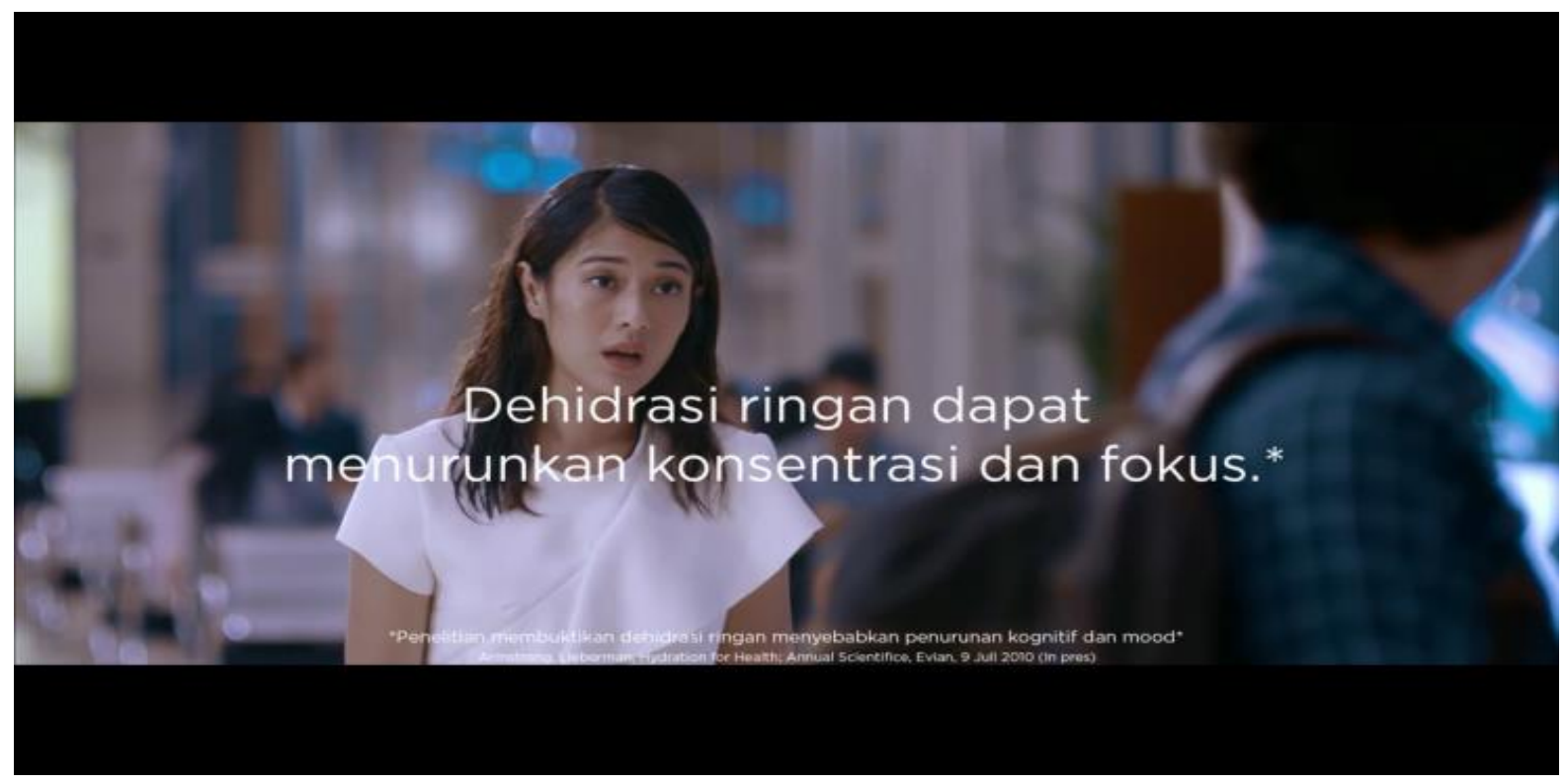

Dari potongan adegan iklan AQUA (data 1) di atas, secara semiotik bisa dijelaskan melalui 3 (tiga) ranah atau level. Pertama, secara denotatif, adegan tersebut di atas adalah betul tentang adegan pertemuan Cinta (yang diperankan oleh Dian Sastrowardoyo) dengan pujaan hatinya yang sudah 14 tahun lamanya tidak bertemu. Tetapi, ternyata tokoh Cinta di dalam adegan tersebut salah menegur atau menyapa kepada seseorang di bandara dengan berucap: "14 tahun saya nunggu kamu!" yang dalam hal ini dikiranya orang tersebut adalah pujaan hatinya dan untuk menutupi rasa malunya tersebut, akhirnya Cinta memutuskan untuk bertanya: “Ada $\boldsymbol{A} \boldsymbol{Q U} \boldsymbol{A}$ ?” Kemudian, adegan iklan AQUA di atas tersebut juga bisa memberikan kesan (image) secara konotatif(connotative level) pada khalayak bahwa adegan tesebut di atas bisa diasosiasikan dengan pesan (message) dan kesan (image) bahwasanya Dian Sastrowardoyo yang berperan sebagai tokoh Cinta saja pun bisa kehilangan fokus dalam mengenali Rangga, pujaan hatinyadi bandara akibat dehidrasi ringan dan tidak membawa air minum mineral AQUA. Nah, berikutnya yang dapat dikaji dari adegan iklan di atas (data 1) adalah melalui segi “mitos" (myth). Menyangkut hal ini, pesan (message) yang secara implicit ingin disampaikan adalah bahwasanya air minum AQUA ini sudah menjadi mitos 170 | http://journal.unesa.ac.id/index.php/paramasastra 
Bunga Diantirta, Analisis Semiotik pada...(hlm. 160 - 176)

brand atau merk air minum yang dikenal secara luas di masyarakat dan bahkan artis sekelas Dian Sastro pun mengkonsumsi AQUA.

Selanjutnya, objek kedua yang dikaji adalah iklan air minum mineral AQUA yang dibintangi oleh actor Nicholas Saputra yang memerankan tokoh Rangga. Nah, di dalam iklan yang dibintangi oleh Nicholas Saputraini memunculkan salah satu adegan yang dikaitkan dengan film Ada Apa Dengan Cinta 2 (AADC2) seperti potongan adegan berikut:

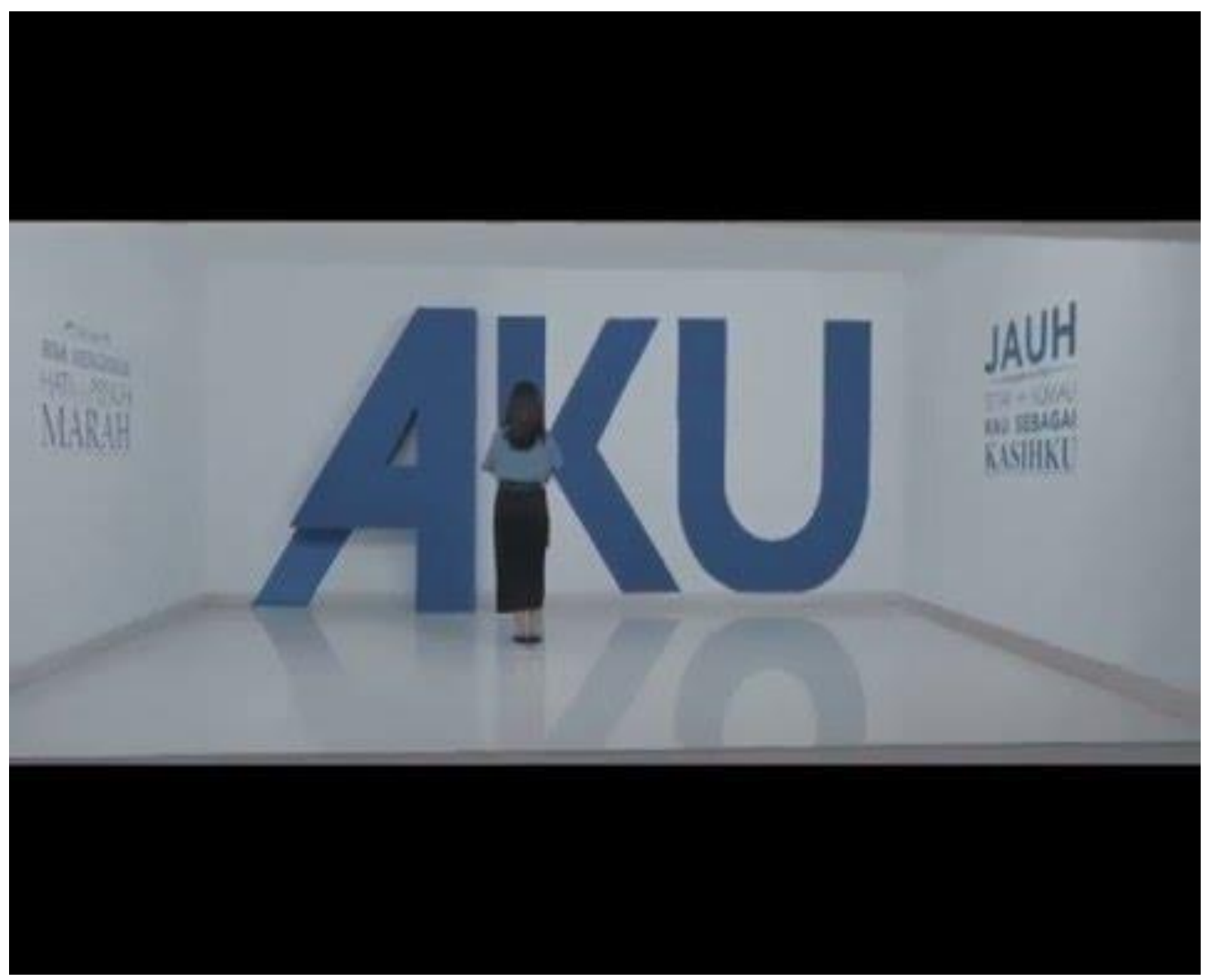

Dari potongan adegan iklan AQUA (data 2) di atas, secara semiotik bisa dijelaskan melalui 3 (tiga) ranah atau level. Pertama, secara denotatif, adegan 
tersebut di atas adalah betul tentang adegan pertemuan Rangga (yang diperankan oleh Nicholas Saputra) dengan pujaan hatinya yang sudah 14 tahun lamanya tidak bertemu. Tetapi, ternyata tokoh Rangga di dalam adegan tersebut hampir salah orang di sebuah museum. Namun, akhirnya Rangga berhasil menemui Cinta, kekasih hatinya sambil mengatakan: “Aku, kamu, kita. 14 tahun berlalu. Jiwa raga kembali bertemu."Nah, yang dimaksud disini, Rangga akhirnya bisa bertemu dengan pujaan hatinya, Cinta karena si Rangga memang fokus mau bertemu Cinta. Kemudian, adegan iklan AQUA di atas tersebut juga bisa memberikan kesan (image) secara konotatif(connotative level) pada khalayak bahwa foto tesebut di atas bisa diasosiasikan dengan pesan (message) dan kesan (image) bahwasanya Nicholas Saputrayang berperan sebagai tokoh Ranggasaja bisa kehilangan fokus akibat tidak membawa air minum mineral AQUA. Nah, berikutnya yang dapat dikaji dari adegan iklan di atas (data 2) adalah melalui segi “mitos" (myth). Menyangkut hal ini, pesan (message) yang secara implicit tampak atau yang ingin disampaikan adalah bahwasanya air minum AQUA ini sudah menjadi mitos brand atau merk air minum yang sudah dikenal secara luas di masyarakat sebagai air minum yang mampu mengatasi dehidrasi ringan dan bahkan actor film sekelas Nicholas Saputra yang memerankan tokoh Rangga di dalam film Ada Apa Dengan Cinta 2 (AADC2) pun mengkonsumsi air minum AQUA sehingga paling tidak bisa meyakinkan khalayak umum, khususnya pemirsa yang melihat iklan itu untuk mengkonsumsi AQUA yang sudah menjadi mitos (myth) sebagai merk (brand) air minum mineral yang mampu meningkatkan focus dan konsentrasi serta mengurangi dehidrasi.

Selanjutnya, objek ketiga yang dijadikan bahan kajian adalah iklan air minum mineral AQUA yang dibintangi oleh comedian Narji “Cagur"dan penyanyi Sandhy Sandoro. Nah, di dalam iklan yang dibintangi oleh comedian Narji “Cagur"dan penyanyi Sandhy Sandoro ini memunculkan adegan dimana 
Bunga Diantirta, Analisis Semiotik pada...(hlm. 160 - 176)

seorang fans yang keliru atau salah mengenali penyanyi Sandhy Sandoro seperti potongan gambar berikut:
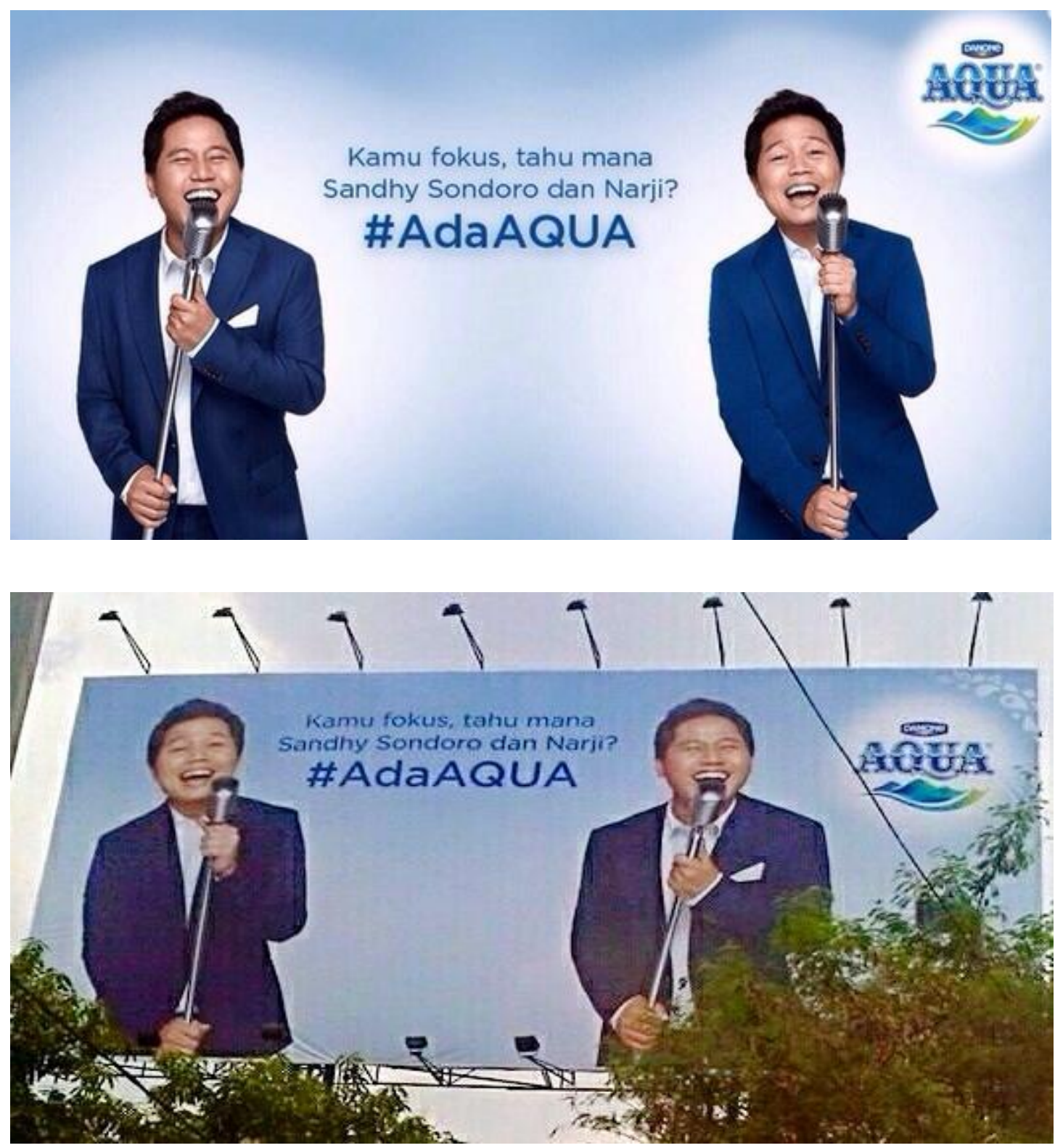

Dari potongan gambar iklan AQUA (data 3) di atas, secara semiotik bisa dijelaskan melalui 3 (tiga) ranah atau level. Pertama, secara denotatif, adegan 
tersebut di atas adalah betul di sebuah pentas atau konser dimana seorang fans keliru atau salah mengenali idolanya (penyanyi Sandhy Sandoro) dan berusaha mengajak orang yang mirip dengan idolanya tersebut, untuk berfoto bareng sambil berujar "Sandhy, selfie bareng dong". Namun, akhirnya si fans itu menyadari kekeliruannya tersebut dengan menutupinya sambil bertanya "Ada $\boldsymbol{A Q U A}$ ?" Kemudian, adegan iklan AQUA di atas tersebut juga bisa memberikan kesan (image) secara konotatif(connotative level) pada khalayak bahwa iklan tesebut di atas bisa diasosiasikan dengan pesan (message) dan kesan (image) bahwasanya seorang fans saja bisa kehilangan fokus dan konsentrasi akibat kurang minum dan tidak mengonsumsi air minum mineral AQUA. Nah, berikutnya yang dapat dikaji dari adegan iklan di atas (data 3) adalah melalui segi "mitos" (myth). Menyangkut hal ini, pesan (message) yang secara implicit tampak atau yang ingin disampaikan adalah bahwasanya air minum AQUA ini sudah menjadi mitos brand atau merk air minum yang sudah dikenal secara luas di masyarakat sebagai air minum yang mampu mengatasi dehidrasi ringan dan bahkan comedian Narji "Cagur" dan penyanyiSandhy Sandoro pun membintangi iklan tentang air minum AQUA tersebut sehingga mungkin saja para khalayak umum, terutama pemirsa yang menonton iklan tersebut dan apalagi yang menjadi fans penyanyi Sandhy Sandoro untuk tertarik mengkonsumsi AQUA yang sudah menjadi mitos (myth) sebagai air minum mineral yang sehat.

Selanjutnya, iklan keempat AQUA yang dijadikan objek kajian dalam makalah ini adalah iklan yang menampilkan comedian Narji “Cagur"sebagai seorang penjual snack dan minuman AQUA yang melayani para pembeli atau konsumen di sebuah kios dagangan. Di dalam iklan ini, secara denotatif (denotative level), yang tampak adalah seorang pembeli wanita yang membeli snack di sebuah kios dan kemudian Narji sebagai pemilik kios menawarinya untuk membeli AQUA dengan berujar: “AQUA-nya nggak sekalian?"dan si wanita pun menjawab: "Ya udah deh boleh satu."Setelah mau membeli 
minuman AQUA tersebut, si wanita ternyata tiba-tiba mengenali kalau si pedagang kios tadi itu ternyata pelawak Narji Cagur dengan berujar: "Narji ya?" sambil menunjukkan poster Narji di iklan yang ditempel di kios dagangan dan kemudian berucap: “ini ada posternya, sama mukanya”.Lalu tiba-tiba si Narji Cagur memanggil teman-teman kru sambil mengatakan: "Weih, ada yang fokus". Dan akhirnya teman-teman kru mendatangi si pembeli wanita itu serta Narji Cagur pun juga mengatakan pada si pembeli wanita itu, “Anda fokus”. Kemudian, menyangkut iklan yang dibintangi comedian Narji Cagur ini, secara konotatif (connotative level), pesan (message) dan kesan (image) yang ditampilkan adalah bahwasanya seorang konsumen atau pembeli saja bisa fokus dan konsentrasi akibat efek membeli air minum AQUA tersebut. Dari sini, bisa diasosiasikan atau dikiaskan bahwa orang yang membeli minuman AQUA itu bisa meningkat fokus dan konsentrasinya. Berikutnya yang dapat dikaji dari adegan iklan di atas (data 3) adalah melalui segi "mitos" (myth). Menyangkut hal ini, pesan (message) yang secara implicit tampak atau yang ingin disampaikan adalah bahwasanya air minum AQUA ini sudah menjadi mitos brand atau merk air minum yang sudah dikenal secara luas di masyarakat sebagai air minum yang mampu mengatasi dehidrasi. Untuk ini pun, bahkan comedian Narji “Cagur” berujar "Ke manapun selalu ada AQUA". Hal ini membuktikan pada khalayak bahwasanya minuman AQUA itu sudah menjadi mitos (myth) dan bahkan melegenda di mana-mana. Di setiap daerah manapun, yang dicari atau ditanyakan oleh orang yang mencari air minum itu pastinya adalah AQUA, meskipun merk air minum yang dijual oleh kios atau toko tersebut itu mungkin saja bukanlah AQUA. Nah, menyangkut hal ini, AQUA sudah menjadi mitos sebagai air minum mineral di manapun kita berada.

\section{SIMPULAN}


Sebagian besar "mitos" yang dikembangkan dalam iklan AQUA adalah air minum AQUA itu sehat dikonsumsi masyarakat. Iklan-iklan Aqua tersebut berhasil meyakinkan khalayak bahwa Aqua memang sebuah merk (brand) pilihan air minum yang sudah menjadi mitos atau melegenda dan tepat dikonsumsi bagi kesehatan terutama dalam mengurangi dehidrasi dan mampu meningkatkan konsentrasi bagi orang yang mengkonsumsinya. Bahkan, artis sekelas Dian Sastrowardoyo pun tidak ketinggalan untuk mengkonsumsi AQUA agar lebih fokus dan konsentrasi serta menghilangkan dehidrasi ringan.

\section{DAFTAR RUJUKAN}

Barthes, Roland. 1972. Mythologies. New York: McGraw and Hill.

Ceasefiremagazine. 2016. (https://ceasefiremagazine.co.uk/in-theory-barthes-

2/) [25 Juni 2016]

Culturalstudiesnow. 2012.

(http://culturalstudiesnow.blogspot.co.id/2012/04/roland-barthes-mythtoday-summary.html) [25 Juni 2012]

Georgetown. 2016. (http://faculty.georgetown.edu/irvinem/theory/Barthes-

Mythologies-MythToday.pdf) [25 Juni 2016]

Welshmythology. 2014. (https://welshmythology.com/2014/11/11/roland-barthes-definitionof-myth/) [25 Juni 2016] 